\title{
COMPARISON OF THE OVERALL MOTION CORRELATION TIMES OF SEVERAL MAMMALIAN SERUM ALBUMINS IN DILUTE SOLUTIONS DETERMINED ON THE BASIS OF MAXWELL EFFECT AND THE DEBYE-STOKES-EINSTEIN EQUATION.
}

\author{
KAROL MONKOS \\ Department of Biophysics, School of Medicine with the Division of Dentistry in Zabrze, Medical University of Silesia, H. Jordana 19, \\ 41-808 Zabrze 8, Poland
}

Received February 02, 2017; accepted April 07, 2017; published online April 19, 2017

\begin{abstract}
One of the rarely used ways of determining the overall motion correlation time of proteins is method based on the Maxwell effect. This effect consists in the appearance of a stimulated birefringence in liquids or solutions and induced by the mechanical force like shear stress in a streamline flow. To determine the overall motion correlation time for protein in dilute solution is sufficient to know the molecular mass and the ratio of the principal axes of protein, and an intrinsic viscosity. The intrinsic viscosity has been measured using an Ubbelohde-type capillary microviscometer immersed in a water-bath controlled thermostatically in the range from $5^{\circ} \mathrm{C}$ to $45^{\circ} \mathrm{C}$ for six mammalian albumins. To check the influence of solution $\mathrm{pH}$ on the overall motion correlation time the intrinsic viscosity value of the human serum albumin in solutions at the isoelectric point and beyond of it was measured. The thus obtained correlation times were compared with the times determined on the basis of the Debye-Stokes-Einstein equation.
\end{abstract}

\section{INTRODUCTION}

Rotational correlation times are frequently used source of information on the dynamics of proteins in solution. In particular, they are helpful in understanding many aspects of the processes occurring at the molecular level (Wüthrich, 2003). Knowledge of that times is of significant value in biophysical characterization of proteins in solution. Because rotational correlation times correlate with the volume and molecular mass of folded proteins, they can provide information about the polymerization and can reveal aggregates formed under the chosen conditions (Danielsen et al, 1991; Lee et al, 2006). In the case of protein solutions rotational correlation times can be set for the water molecules of the solution (bulk water), the water molecules of hydration layer of proteins, protein side-chains or the whole protein (Kakalis \& Kumosinski, 1992). In the latter case, the rotational correlation time is called the overall motion correlation time. Depending on the experimental method used correlation times connected with tensors of different rank are obtained. For example, they can be connected with a dipole moment (rank-1 tensor) $\tau_{1}$ or protein polarizability (rank-2 tensor) $\tau_{2}$. The exact definition of the correlation time associated with the tensor of arbitrary rank has been given in the earlier work (Monkos, 2007a).

For proteins correlation time $\tau_{1}$ can be measured by dielectric spectroscopy (Kabir et al, 2003; Miura et al, 1994; Grant et al, 1971; Moser et al, 1966) while the time $\tau_{2}$ in fluorescence anisotropy measurements (Zorrilla et al, 2007; Kuttner et al, 2005; Zorrilla et al, 2004; Feinstein et al, 2003; Kamal \& Behere, 2002; Ferrer et al, 2001; Bialik et al, 1998; Takeda et al, 1991; Takeda \& Yamamoto, 1990; Bucci \& Steiner, 1988; Gryczynski et al, 1988), EPR spectroscopy (Cavalu et al, 2002; Hustedt et al, 1993; Steinhoff, 1990; Steinhoff et al, 1989; Steinhoff, 1988; Ebert et al, 1981), NMR spectroscopy (Yilmaz et al, 2014; Yao et al, 2008; Luchinat \& Parigi, 2007; Budak et al, 2006; Lee et al, 2006; Korchuganov et al, 2004; Denisov et al, 2004; Denisov \& Halle, 1995a, 1995b; Kakalis \& Kumosinski, 1992), perturbed angular correlations of $\gamma$-rays method (Danielsen et al, 1991) and by using Maxwell effect (Monkos, 2007a; Ferrer et al, 2001; Acuña et al, 1987). Quite recently a method for determining the correlation times based on modeling and numerical methods has been developed (Rezaei-Ghaleh et al, 2015). However, results presented for a given protein in different publications can vary significantly. As far as I know - 
for proteins - the correlation times associated with tensors of higher ranks have not yet been measured.

The correlation times of arbitrary rank $\mathrm{n}$ are related to the rotational diffusion coefficient $D_{r}$ by a simple relationship: $\tau_{n}=\left[n(n+1) D_{r}\right]^{-1}$. Thus, the correlation times of different ranks are interconnected: $\tau_{1}=3 \tau_{2}=$ $6 \tau_{3}$ and so on. In this study, the overall motion correlation time $\tau_{2}$ for several mammalians albumin was determined based on Maxwell effect. The results were compared with the theoretical values of correlation times obtained on the basis of the Debye-Stokes-Einstein equation.

\section{MATERIALS}

The following products of the Sigma Chemical Co. were used in this study: bovine serum albumin BSA (A 4503), equine serum albumin ESA (A 9888), human serum albumin HSA at pH 7.0 (A 1653), ovine serum albumin OSA (A 3264), porcine serum albumin PSA (A 2764) and rabbit serum albumin RSA (A 0639). HSA at pH 4.7 (lyophilized, purity $99 \%$ and essentially fatty acid- and globulin-free) was purchased from Polish Chemical Reagents factories. Albumins were used without further purification for all the measurements. From the crystalline form the albumins were dissolved in distilled water and then filtered by means of filter papers in order to remove dust particles and possible undissolved fragments. The samples were stored in a refrigerator until just prior to viscometry measurements, when they were warmed from 5 to $45^{\circ} \mathrm{C}$, mainly by steps of $5^{\circ} \mathrm{C}$. The $\mathrm{pH}$ values of thus prepared solutions were as follows: 5.2 for BSA, 7.4 for ESA, 7.0 or 4.7 for HSA, 7.05 for OSA, 6.6 for PSA and 7.0 for RSA. These values changed only slightly with a change in solution concentration. The above values are the mean values of
$\mathrm{pH}$. The isoelectric point $\mathrm{pI}$ of the studied albumins is: $(4.7$ - 5.4) for BSA, $(4.65$ - 4.9) for ESA, (4.7 - 4.95) for HSA, (4.6 - 4.9) for OSA, (4.6 - 4.9) for PSA and (4.6 - 5.3) for RSA (Miller \& Gemeiner, 1998). Thus, BSA and HSA at $\mathrm{pH} 4.7$ were studied in their isoelectric point, and the other albumins above their isoelectric point.

\section{VISCOMETRY}

The viscosity measurements of albumins solutions were conducted using an Ubbelohde-type capillary microviscometer immersed in a water bath controlled thermostatically at $(5-45)^{\circ} \mathrm{C}$ with a precision of $\pm 0.1^{\circ} \mathrm{C}$. The microviscometer was calibrated using cooled boiled distilled water and a flow time for water was $28.5 \mathrm{~s}$ at $25^{\circ} \mathrm{C}$. A solution passed once through the viscometer before any measurements were made. Measurements started after a few minutes delay to make sure that the system has reached thermal equilibrium. They were usually made in intervals of $5^{\circ} \mathrm{C}$. Flow times were recorded to within $0.1 \mathrm{~s}$. The upper temperature of viscosity measurement has been selected by the denaturation temperature of albumins. At temperatures slightly higher than $45^{\circ} \mathrm{C}$ the thermal denaturation of the studied albumins occurs and the lower the albumin concentration the higher the denaturation temperature. For temperatures above the denaturation temperature, the viscosity of albumins solutions increases with increasing temperature.

Solution densities were measured by weighing. Albumin concentrations were determined using a dry method in which the samples were dried at high temperature for several hours.

Table 1 . The numerical values of the intrinsic viscosity $[\eta] \times 10^{3}\left[\mathrm{~m}^{3} / \mathrm{kg}\right]$ for all investigated albumins.

\begin{tabular}{|c|c|c|c|c|c|c|c|}
\hline $\mathrm{t}\left[{ }^{\circ} \mathrm{C}\right]$ & $\begin{array}{c}\mathrm{BSA} \\
\mathrm{pH}=\mathrm{pI}\end{array}$ & $\begin{array}{c}\text { HSA } \\
\mathrm{pH}=\mathrm{pI}\end{array}$ & $\begin{array}{c}\text { HSA } \\
\mathrm{pH}>\mathrm{pI}\end{array}$ & $\begin{array}{c}\text { RSA } \\
\mathrm{pH}>\mathrm{pI}\end{array}$ & $\begin{array}{c}\text { OSA } \\
\mathrm{pH}>\mathrm{pI}\end{array}$ & $\begin{array}{c}\text { ESA } \\
\mathrm{pH}>\mathrm{pI}\end{array}$ & $\begin{array}{c}\text { PSA } \\
\mathrm{pH}>\mathrm{pI}\end{array}$ \\
\hline 5 & $6.49 \pm 0.16$ & $6.46 \pm 0.10$ & $4.90 \pm 0.12$ & $5.21 \pm 0.13$ & $4.95 \pm 0.12$ & $4.38 \pm 0.11$ & $4.36 \pm 0.11$ \\
\hline 10 & $6.26 \pm 0.15$ & $6.30 \pm 0.10$ & $4.83 \pm 0.12$ & $5.12 \pm 0.13$ & $4.87 \pm 0.12$ & $4.31 \pm 0.11$ & $4.28 \pm 0.10$ \\
\hline 15 & $6.06 \pm 0.15$ & $6.18 \pm 0.10$ & $4.78 \pm 0.12$ & $5.05 \pm 0.12$ & $4.80 \pm 0.12$ & $4.25 \pm 0.10$ & $4.22 \pm 0.10$ \\
\hline 20 & $5.90 \pm 0.14$ & $6.10 \pm 0.10$ & $4.73 \pm 0.12$ & $4.99 \pm 0.12$ & $4.74 \pm 0.12$ & $4.19 \pm 0.10$ & $4.17 \pm 0.10$ \\
\hline 25 & $5.78 \pm 0.14$ & $6.06 \pm 0.10$ & $4.69 \pm 0.12$ & $4.94 \pm 0.12$ & $4.69 \pm 0.12$ & $4.14 \pm 0.10$ & $4.13 \pm 0.10$ \\
\hline 30 & $5.69 \pm 0.14$ & $6.07 \pm 0.11$ & $4.66 \pm 0.11$ & $4.91 \pm 0.12$ & $4.65 \pm 0.11$ & $4.09 \pm 0.10$ & $4.10 \pm 0.10$ \\
\hline 35 & $5.63 \pm 0.14$ & $6.11 \pm 0.11$ & $4.63 \pm 0.11$ & $4.89 \pm 0.12$ & $4.62 \pm 0.11$ & $4.05 \pm 0.10$ & $4.08 \pm 0.10$ \\
\hline 40 & $5.60 \pm 0.14$ & $6.18 \pm 0.12$ & $4.62 \pm 0.11$ & $4.87 \pm 0.12$ & $4.60 \pm 0.11$ & $4.01 \pm 0.10$ & $4.08 \pm 0.10$ \\
\hline 45 & $5.60 \pm 0.14$ & $6.29 \pm 0.13$ & $4.61 \pm 0.11$ & $4.87 \pm 0.12$ & $4.59 \pm 0.11$ & $3.98 \pm 0.10$ & $4.08 \pm 0.10$ \\
\hline
\end{tabular}

The main purpose of measuring the viscosity of albumins solutions was determination of their intrinsic viscosity. According to the definition, the intrinsic viscosity $[\eta]=\lim _{c \rightarrow 0} \eta_{s p} / c$, where the specific viscosity $\eta_{s p}=\eta_{r}-1$ and $c$ is the solute concentration in $\mathrm{kg} / \mathrm{m}^{3}$. The relative viscosity, in turn, $\eta_{r}=\eta / \eta_{o}$ and $\eta$ and $\eta_{o}$ denote the viscosity of a solution and the solvent, respectively. The traditional method for determining the 
intrinsic viscosity is based on the plotting of $\eta_{s p} / c$ on the concentration and extrapolating it to the intersection with the axis of coordinates. The value of the intersection is equal to the intrinsic viscosity. In this study we used a different method proposed earlier (Monkos, 1996). This method has been successfully applied to various globular and non-globular proteins (Monkos, 2007b). The numerical values of [ $\eta]$ obtained by this method for temperatures from $5^{\circ} \mathrm{C}$ to $45^{\circ} \mathrm{C}$ are shown in Table 1 (Monkos, 1996, 2004, 2005a, 2005b, 2013). They will be used for the calculation of the overall motion correlation time of albumins on the basis of Maxwell effect.

\section{RESULTS AND DISCUSSION}

\section{$\tau_{2}$ from the Maxwell effect}

A simulated birefringence in liquids or solutions induced by the mechanical force like shear stress in a streamline flow is called Maxwell effect (Raman \& Krishnan, 1927). The effect appears when the molecules of a flowing liquid or molecules dissolved in a solution are non-spherical in shape and have anisotropic polarizability (Cwietkow et al, 1968). The flow of a suspension of rigid molecules having the shape of ellipsoids of revolution was examined by Jeffery on the basis of the phenomenological Navier-Stokes equations (Jeffery, 1923). Jeffery showed that the resultant of stresses acting on the surface of such ellipsoid is equivalent to the action of two couples of forces. The first of them is trying to direct the orientation of the principal axis of the molecule according to the direction of liquid flow and the second one is trying to direct its orientation in the direction perpendicular to the flow direction. The simultaneous action of these couples causes that movement of the ellipsoid becomes periodic, ie. its main axis of symmetry precesses around the axis perpendicular to the direction of fluid flow. In a laminar flow rate of precession is dependent on the size of the principal axes of the molecule and the velocity gradient. It appears that the major axes of the molecules form with a flow direction different angles, and the distribution function describing their spatial arrangement becomes anisotropic. At low temperatures, when the Brownian motion is negligible, distribution function takes the maximum value when the direction of the major axis of the molecule is parallel to the direction of flow. In other words, hydrodynamic forces in laminar flow tend to set the major axis of the asymmetric molecules in the flow direction. However, at higher temperatures, this forced orientation of molecules induced by the flow of liquid is weakened by the rotational Brownian motion of molecules. At constant velocity gradient in the solution a stationary distribution of the orientation of the principal axes of the molecules is established and the privileged direction of the molecules orientation makes some angle with the direction of the liquid flow. When the considered molecules are optically anisotropic their non-uniform distribution leads to a macroscopic anisotropy in the solution.

In the steady-state, the anisotropy of the spatial orientation of the main axis of the molecules can be described by a distribution function of all possible directions which satisfies equation of diffusion type (Cwietkow et al, 1968). If the external mechanical stresses that force the movement of the liquid disappear, anisotropy of the distribution of orientation of the molecules principal axes disappears due to their rotational Brownian motion. The time at which the distribution function is reduced by a factor of $\mathrm{e}^{-1}$ is called the overall motion correlation time and it is equivalent to the rotational correlation time $\tau_{2}$ (Cwietkow et al, 1968).

The overall motion correlation time can be evaluated on the basis of Maxwell effect for prolate ellipsoids of revolution only for the dilute solutions. It uses then the following relationship (Cwietkow et al, 1968; Acuña et al, 1987; Ferrer et al, 2001):

$$
\tau_{2}=\frac{M\left[\eta \left\lceil\eta_{o}\right.\right.}{R T F(p)}
$$

where $M, R$ and $T$ are the molecular mass of the molecules in solution, gas constant and the absolute temperature, respectively; $F(p)$ is a function of the axial ratio $p=a / b$ of dissolved molecules modeled as a prolate ellipsoids of revolution with one long semi-axis (a) and two shorter semi-axes $(b)$. This function can be represented as $F(p)=v / 6 \Pi$, where $v$ is a Simha factor (Simha, 1940) and $\Pi$ is the Perrin function (Perrin, 1934).

In his original work Simha showed how to calculate the value of the factor $v$ for triaxial ellipsoid. Expressions obtained by him contain elliptic integrals that can be solved numerically. However, for prolate ellipsoids of revolution relationship between $v$ and $p$ can be determined from the asymptotic relations given by Harding (Harding, 1997):

$$
\begin{aligned}
& p=-10.71584+2.79158 v+1.622009 v^{2}+ \\
& +0.0155616 q^{3}-0.192997 v^{4}+ \\
& +0.0206071 s^{5}
\end{aligned}
$$

for $(1.1 \leq p<2)$, and 


$$
\begin{aligned}
& p=-3.80413+2.8712 v-0.3908319 v^{2}+ \\
& +0.03612282 v^{3}-0.001733981 v^{4}+ \\
& +0.0000332711 v^{5}
\end{aligned}
$$

for $(2 \leq p<10)$.

The Perrin function, in turn, has the following form:

$$
\Pi \equiv\left[\frac{0.4}{2 g_{1}^{-1}+4 g_{2}^{-1}}+\frac{0.4}{5 g_{1}^{-1}+g_{2}^{-1}}+\frac{0.2}{6 g_{1}^{-1}}\right]
$$

where

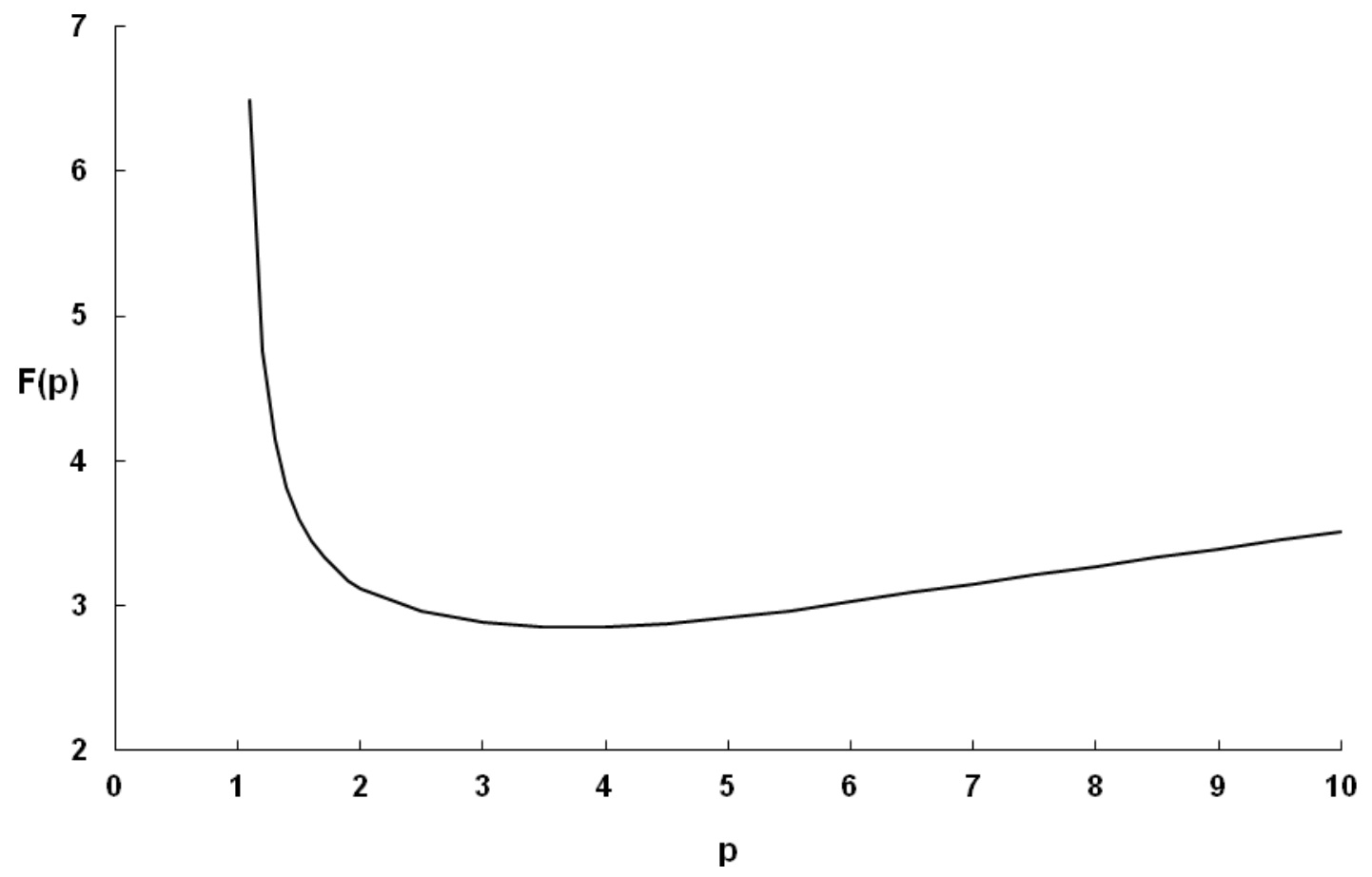

Fig. 1. Plot of the function $F(p)=v / 6 \Pi$ vs. axial ratio $p$, according to formulae (2) - (6).

Mammalian serum albumins are moderately large proteins, with primary structure constituted by a single polypeptide chain of about 580 amino-acid residues and molecular mass $\mathrm{M}_{\mathrm{p}}=66.479 \mathrm{kDa}$ for HSA and $\mathrm{M}_{\mathrm{p}}=$ $66.5 \mathrm{kDa}$ for the other studied here albumins (Dockal et al, 1999). These albumins exhibit high amino-acid sequence identity with each other and this leads to the expectation of the similar (but not identical) overall shape of them. This was confirmed among other by examining the three-dimensional structure of HSA, BSA and ESA by X-ray crystallography (He et al, 1992; Ho et al, 1993; Carter \& Ho, 1994). However, under physiological conditions, albumins are in aqueous

$$
g_{1}=\frac{2\left(p^{2}-1\right)}{3 p(p-S)} \quad, \quad g_{2}=\frac{2\left(p^{4}-1\right)}{3 p\left(2 p^{2}-1\right) S-p}
$$

and

$$
S=\frac{\ln \left(p+\sqrt{p^{2}-1}\right)}{\sqrt{p^{2}-1}}
$$

Figure 1 shows the function $F(p)$ for globular proteins, ie. for molecules for which $1 \leq p \leq 10$. 
and BSA (Nesmelova et al, 2002). Obtained results are shown in Table 2.

The measure of protein hydration is the hydration level $\delta$, defined in terms of the time-averaged mass of water associated with a protein per unit anhydrous mass of protein. It does not depend on temperature (Ferrer et al. 2001). The molecular mass of hydrated albumin is composed of the molecular mass of unhydrated albumin
$M_{p}$ and the mass of hydration shell of water surrounding the albumin molecule in solution: $M=M_{p}(1+\delta)$. For HSA $\delta=0.379$ (Baranowska \& Olszewski, 1996) and for the other studied here albumins $\delta=0.35$ (Squire \& Himmel, 1979). This gives a hydrodynamic mass of HSA $M=91.675 \mathrm{kDa}$ and for the other studied here albumins $M=89.775 \mathrm{kDa}$.

Table 2. The numerical values of the major semi-axis $(a)$, the minor semi-axes $(b)$, the hydrodynamic radius $\left(R_{h}\right)$, the axial ratio $p$, the Simha factor $v$ (from the relation (3)), the Perrin's function $\Pi$ (from the formula (4)), and the function $F(p)=$ $v / 6 \Pi$ for discussed albumins.

\begin{tabular}{cccccccc}
\hline Albumin & $a[\mathrm{~nm}]$ & $b[\mathrm{~nm}]$ & $R_{h}[\mathrm{~nm}]$ & $p$ & $v$ & $\Pi$ & $F(p)=v / 6 \Pi$ \\
\hline Human & 8.2 & 2.1 & 3.89 & 3.95 & 4.61 & 0.270 & 2.85 \\
Bovine & 7.7 & 2.2 & 3.83 & 3.50 & 4.16 & 0.243 & 2.85 \\
Equine & 7.16 & 2.27 & 3.74 & 3.15 & 3.84 & 0.223 & 2.87 \\
Ovine & 7.41 & 2.42 & 3.92 & 3.06 & 3.76 & 0.217 & 2.88 \\
Porcine & 7.18 & 2.31 & 3.78 & 3.11 & 3.80 & 0.220 & 2.87 \\
Rabbit & 7.75 & 2.39 & 4 & 3.25 & 3.93 & 0.229 & 2.86 \\
\hline
\end{tabular}

The molecular mass and the axial ratio of hydrated albumins, as well as experimentally determined intrinsic viscosity values allow to calculate their overall motion correlation time from equation (1). The numerical values of $\tau_{2}$ for all investigated here albumins are gathered in Table 3.

Table 3. The numerical values of the overall motion correlation time $\tau_{2}[\mathrm{~ns}]$ for all investigated albumins obtained on the basis of equation (1).

\begin{tabular}{cccccccc}
\hline $\mathrm{t}\left[{ }^{\circ} \mathrm{C}\right]$ & $\begin{array}{c}\mathrm{BSA} \\
\mathrm{pH}=\mathrm{pI}\end{array}$ & $\begin{array}{c}\mathrm{HSA} \\
\mathrm{pH}=\mathrm{pI}\end{array}$ & $\begin{array}{c}\mathrm{HSA} \\
\mathrm{pH}\rangle \mathrm{pI}\end{array}$ & $\begin{array}{c}\text { RSA } \\
\mathrm{pH}\rangle \mathrm{pI}\end{array}$ & $\begin{array}{c}\text { OSA } \\
\mathrm{pH}\rangle \mathrm{pI}\end{array}$ & $\begin{array}{c}\text { ESA } \\
\mathrm{pH}\rangle \mathrm{pI}\end{array}$ & $\begin{array}{c}\text { PSA } \\
\mathrm{pH}\end{array}$ pI \\
\hline 5 & $134 \pm 3.3$ & $137 \pm 2.1$ & $104 \pm 2.5$ & $107 \pm 2.6$ & $101 \pm 2.5$ & $90.1 \pm 2.2$ & $89.3 \pm 2.2$ \\
10 & $110 \pm 2.7$ & $113 \pm 1.8$ & $86.3 \pm 2.1$ & $89.2 \pm 2.2$ & $84.3 \pm 2.1$ & $74.9 \pm 1.8$ & $74.3 \pm 1.8$ \\
15 & $90.9 \pm 2.2$ & $94.5 \pm 1.5$ & $73.1 \pm 1.8$ & $75.4 \pm 1.8$ & $71.2 \pm 1.7$ & $63.2 \pm 1.5$ & $62.7 \pm 1.5$ \\
20 & $76.6 \pm 1.9$ & $80.9 \pm 1.3$ & $62.7 \pm 1.6$ & $64.5 \pm 1.6$ & $60.9 \pm 1.5$ & $54.0 \pm 1.3$ & $53.7 \pm 1.3$ \\
25 & $65.6 \pm 1.6$ & $70.3 \pm 1.2$ & $54.4 \pm 1.4$ & $55.9 \pm 1.4$ & $52.7 \pm 1.3$ & $46.6 \pm 1.1$ & $46.5 \pm 1.1$ \\
30 & $56.9 \pm 1.4$ & $62.0 \pm 1.1$ & $47.6 \pm 1.1$ & $48.9 \pm 1.2$ & $46.1 \pm 1.1$ & $40.6 \pm 1.0$ & $40.7 \pm 1.0$ \\
35 & $50.0 \pm 1.2$ & $55.6 \pm 1.0$ & $42.1 \pm 1.0$ & $43.2 \pm 1.1$ & $40.7 \pm 1.0$ & $35.7 \pm 0.9$ & $36.0 \pm 0.9$ \\
40 & $44.4 \pm 1.1$ & $50.0 \pm 1.0$ & $37.4 \pm 0.9$ & $38.5 \pm 0.9$ & $36.2 \pm 0.9$ & $31.6 \pm 0.8$ & $32.1 \pm 0.8$ \\
45 & $39.9 \pm 1.0$ & $45.8 \pm 1.0$ & $33.6 \pm 0.8$ & $34.6 \pm 0.8$ & $32.4 \pm 0.8$ & $28.2 \pm 0.7$ & $28.8 \pm 0.7$ \\
\hline
\end{tabular}

As can be seen the values of $\tau_{2}$ obtained - at the same temperature - for the studied albumins in solutions at $\mathrm{pH}$ higher than their pI differ little from each other. Comparison of the numerical values of $\tau_{2}$ for HSA obtained in solutions at $\mathrm{pH}=\mathrm{pI}$ and $\mathrm{pH}>\mathrm{pI}$ shows that the correlation time obtained for the albumin in solution at $\mathrm{pH}=\mathrm{pI}$ is significantly higher than in the solution at $\mathrm{pH}>\mathrm{pI}$. Furthermore, the correlation times $\tau_{2}$ obtained for HSA and BSA in solutions at $\mathrm{pH}=\mathrm{pI}$ have similar values. In solutions at $\mathrm{pH}>\mathrm{pI}$ molecules of albumins are charged as a whole. The Coulomb repulsion between two molecules of albumin partially balances the attractive forces caused mainly by dipole-dipole interaction. As a result, the resultant force of interaction between two molecules is low. Contrary to this, in solutions at $\mathrm{pH}=\mathrm{pI}$ the net charge on the albumins is equal to zero and the attractive forces connected with the dipole-dipole interaction prevail. It is obvious that attractive forces between the molecules slows down their rotational movement. So, the resultant forces between two molecules are greater the rotational correlation times should be longer. Since the resultant forces between the molecules are the greatest in solutions at $\mathrm{pH}=\mathrm{pI}$ therefore can be hypothesized, that for a given protein and at a fixed temperature the correlation times take then the maximum value.

It should be emphasized that from the relation (1) the overall motion correlation time can be determined only when molecules in solution are approximated as a prolate ellipsoids of revolution. For random coil polymers the overall motion correlation time can be calculated from the following formula (Isihara, 1968):

$$
\tau_{2}=\frac{2 M[\eta] \eta_{o}}{3 R T}
$$


For example, the above equation were used to determine $\tau_{2}$ for the complex branched polysaccharides: hetero-polysaccharide pullulan (Dais \& Vlachou, 2001) and scleroglucan (Vlachou et al, 2001). In modeling the dynamics of this type of polysaccharides, two types of motions are considered: (i) the overall rotational motion of the carbohydrate chain as a whole, and (ii), local chain motions. Usually the overall motion is much slower than the chain local motions. Since in ${ }^{13} \mathrm{C}$ relaxation NMR measurements - commonly used in studies of polysaccharides - all carbons in the carbohydrate chain relax via both the overall and local motions this method does not allow separate the overall motion and the local chain motions. However, the overall motion correlation time estimated from equation (7) can help in their separation.

\section{$\tau_{2}$ from the Debye-Stokes-Einstein equation}

The problem of the translational and rotational diffusion of spherical molecules immersed in an ideal, homogeneous, isotropic and continuous solvent was considered in fluctuation-dissipation theory by Einstein (Einstein, 1956). In this theory, it is assumed that the size of the solvent molecules is negligibly small compared to the size of the dissolved molecules. It means that the dissolved molecules can be treated as Brownian particles. This condition is satisfied for the aqueous solutions of proteins. This theory assumes then that in dilute solutions the interaction between the solute molecules are negligible and the interactions between these molecules and the molecules of the solvent can be replaced by randomly fluctuating forces. Translational and rotational diffusion of Brownian particles is driven by thermal energy and is hindered by friction experiences by them. Einstein's theory along with the results of macroscopic continuum hydrodynamics (Landau \& Lifshits, 1959) allows to determine the coefficients of the translation and rotation diffusion of the macromolecules in dilute solutions. The obtained result for the rotational diffusion coefficient can be used to determine the overall motion correlation time. For the correlation time connected with the 1-rank tensor, we get the so-called Debye-Stokes-Einstein (DSE) equation:

$$
\tau_{l}=\frac{8 \pi \eta R_{h}^{3}}{l(l+1) k T}
$$

where $k$ is Boltzmann constant, $\eta$ is solution viscosity and $R_{h}$ denotes the hydrodynamic radius of the macromolecules in solution. For spherical molecules, the hydrodynamic radius $R_{h}$ is equal to their radius. Generally, the hydrodynamic radius of non-spherical molecule is interpreted as the radius of the spherical molecule with the same diffusion coefficient.
The problem of translational and rotational diffusion of molecules modeled by a prolate or oblate ellipsoid of revolution was also studied by Perrin (Perrin, 1936). According to this theory for molecules modeled by a prolate ellipsoid of revolution, the hydrodynamic radius can be expressed by its major and minor semi-axes in the following way:

$$
R_{h}=\frac{\sqrt{a^{2}-b^{2}}}{\ln \left(\frac{a+\sqrt{a^{2}-b^{2}}}{b}\right)}
$$

The size of major and minor semi-axes of molecules otherwise affect the value of their hydrodynamic radius. To see this is sufficient to express the hydrodynamic radius per unit of major and minor semi-axes of molecule by the axial ratio $p$ :

$$
\begin{aligned}
& \frac{R_{h}}{a}=\frac{\sqrt{1-p^{-2}}}{\ln \left[p\left(1+\sqrt{1-p^{-2}}\right)\right]} \\
& \frac{R_{h}}{b}=\frac{\sqrt{p^{2}-1}}{\ln \left(p+\sqrt{p^{2}-1}\right)}
\end{aligned}
$$

These relationships are presented graphically in Figure 2.

It has been experimentally proved, for native BSA and HSA, that the hydrodynamic radius does not depend on solution $\mathrm{pH}$ and temperature (Jachimska et al, 2008). In Table 2 are given the numerical values of the major semi-axis $(a)$ and the minor semi-axes $(b)$ for hydrated albumins investigated in this work. On this basis, their hydrodynamic radius can be calculated from the equation (9). The results are also shown in Table 2. It is evident that the hydration layer increases the hydrodynamic radius of the albumin molecule compared to the radius of the unhydrated molecule and slows the rotational motion.

DSE relation (Eq. 8) for correlation times connected with 2-rank tensors has the form:

$$
\tau_{2}=\frac{4 \pi \pi \eta_{h}^{3}}{3 k T}
$$

The correctness of the above equation for globular proteins in dilute solutions has been demonstrated by many authors (Yilmaz et al, 2008; Zorrilla et al, 2004; Zeeb et al, 2003; Van-Quynh et al, 2003; Ferrer et al, 2001; Lavalette et al, 1999; Steinhoff 1990). According 
to the above relationship the overall motion correlation time is proportional to solution viscosity and the plot of $\tau_{2}$ depending on $\eta / T$ is linear. Deviations from linearity are observed for the relative viscosity of the solution above 2 (Zeeb et al, 2003). Deviations from the DSE equation appear also when the assumptions of continuity and homogeneity of solvent are not fulfilled. This situation occurs when the viscosity of the solution of proteins is adjusted by adding viscous cosolvents (like dextrans) of various size and mass. In this case to describe the rotational Brownian motion of proteins in a macromolecular environment the linear dependence of $\tau_{2}$ on $\eta$ in the SED equation must be replaced by a power law: $\tau_{2} \sim \eta^{\mathrm{k}}$. The exponent " $\mathrm{k}$ " of the power law expresses the fact that the protein experiences only a fraction of the hydrodynamic interactions of macromolecular cosolvent and it depends on protein size and cosolvent's mass (Lavalette et al, 1999; Steinhoff, 1990).

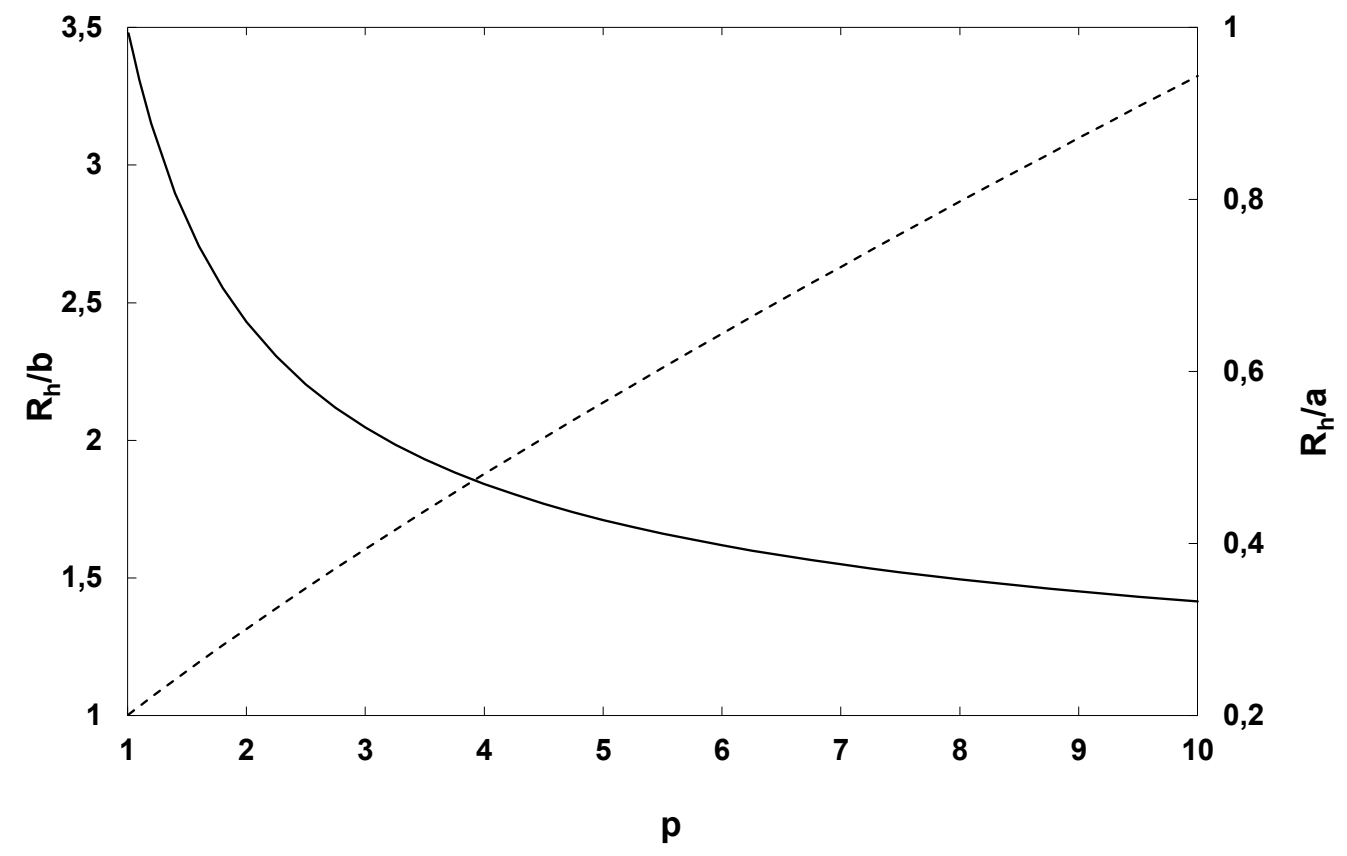

Fig. 2. Plot of the hydrodynamic radius per unit of major axis (-) and minor axis (---) of ellipsoid of revolution vs. axial ratio according to equations (10) and (11), respectively.

Since the size of the water molecules is negligibly small relative to the size of proteins, and in particular to a size of albumin molecules, so the latter can be regarded as Brownian particles. This means that equation (12) can be used to determine the overall motion correlation times for dilute solutions of albumins. Using the values of the hydrodynamic radius of hydrated molecules of albumins from the Table 2, the values of the overall motion correlation time $\tau_{2}$ for the studied here albumins were calculated. The results are presented in Table 4.

Table 4. The numerical values of the overall motion correlation time $\tau_{2}[\mathrm{~ns}]$ from DSE equation for all investigated albumins.

\begin{tabular}{ccccccc}
\hline $\mathrm{t}\left[{ }^{\circ} \mathrm{C}\right]$ & $\mathrm{BSA}$ & $\mathrm{HSA}$ & $\mathrm{RSA}$ & OSA & ESA & PSA \\
\hline 5 & 93.1 & 97.4 & 106 & 99.8 & 86.7 & 89.2 \\
10 & 80.1 & 82.3 & 89.7 & 84.4 & 73.3 & 75.4 \\
15 & 67.5 & 70.6 & 76.8 & 72.3 & 62.8 & 64.6 \\
20 & 58.4 & 61.1 & 66.6 & 62.7 & 54.4 & 56.0 \\
25 & 51.1 & 53.4 & 58.2 & 54.8 & 47.6 & 49.0 \\
30 & 45.0 & 47.1 & 51.3 & 48.3 & 41.9 & 43.1 \\
35 & 40.0 & 41.8 & 45.5 & 42.9 & 37.2 & 38.3 \\
40 & 35.7 & 37.4 & 40.7 & 38.3 & 33.3 & 34.2 \\
45 & 32.1 & 33.6 & 36.5 & 34.4 & 29.9 & 30.7 \\
\hline
\end{tabular}


It is interesting to compare these values with the values of $\tau_{2}$ obtained by using the Maxwell method (see Table 3 ). As can be seen $\tau_{2}$ values obtained for a given albumin at a fixed temperature from the DSE equation are very similar (and in some cases nearly identical) to values of the times obtained from the Maxwell method, but only for albumins in solutions at $\mathrm{pH}>\mathrm{pI}$. The values of the times $\tau_{2}$ obtained by the Maxwell effect for $\mathrm{BSA}$ and HSA in solutions at $\mathrm{pH}=\mathrm{pI}$ are substantially greater than the corresponding times obtained from the DSE equation. As mentioned above, in solutions at $\mathrm{pH}=$ pI the net charge on the albumins is equal to zero and the attractive forces connected with the dipole-dipole interaction prevail. The obtained results show that in solutions at $\mathrm{pH}=\mathrm{pI}$ this interaction greatly affects the rotational diffusion of albumins, even in dilute solutions.

The above results clearly show that the value of the overall motion correlation time depends on both the type of albumin, solution $\mathrm{pH}$ and temperature. Unfortunately, it is difficult to compare values of $\tau_{2}$ presented here with the values obtained by other methods, because the authors often do not provide the type of studied albumin as well as the solution $\mathrm{pH}$ and temperature. For HSA at $25^{\circ} \mathrm{C}$ in solution at concentration $0.94 \mathrm{mM}$ and $\mathrm{pH} 7.4$ the value $\tau_{2}=63 \mathrm{~ns}$ has been obtained (Luchinat \& Parigi, 2007). For BSA in dilute solution the following values of $\tau_{2}$ have been reported: $54.8 \mathrm{~ns}$ (at $\mathrm{t}=18^{\circ} \mathrm{C}$ )

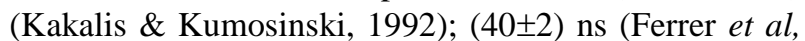
2001), $48.2 \mathrm{~ns}$ and $41.7 \mathrm{~ns}$ (at $\mathrm{t}=20^{\circ} \mathrm{C}$ ) (Bucci \& Steiner, 1988); $41 \mathrm{~ns}$ (at $\mathrm{t}=27^{\circ} \mathrm{C}$ ) (Van-Quynh et al, 2003); and $76 \mathrm{~ns}$ (at $\mathrm{t}=25^{\circ} \mathrm{C}$ ) (Moser et al, 1966). As can be seen, these values are of the same order of magnitude as those obtained by the present study. To my knowledge there is no corresponding data in the literature for the correlation time $\tau_{2}$ for other types of albumin.

The investigation of rotational motion of proteins through different experimental methods is complicated by the presence of several potentially coupled motions. As appears, proteins exhibit besides Brownian rotation of the entire macromolecular framework, motions ranging from local vibrations of atoms and groups through global changes of relative positions of whole domains to rotations of side chains, over an exceedingly wide time extending from fractions of picoseconds to seconds (Acuña et al, 1987). Evidence for internal motions in globular proteins, reflecting the presence of molecular flexibility has come from a number of different experimental approaches. For example, the time-resolved depolarization of the intrinsic fluorescence (tryptophan) of proteins contains a very fast decay time due to the segmental motions of the tryptophan with respect to the rest of the protein as well as a much slower one corresponding to the global Brownian rotation of the protein (Ferrer et al, 2001;
Kamal \& Behere, 2002). In turn, the EPR spectrum of a bound spin label reflects the rotational motion of the protein itself, the fluctuation of protein domains, or some residual motion of the label (which may be regarded as an artificial amino acid chain) with respect to the whole protein (Steinhoff et al, 1989; Steinhoff, 1990). Similarly, in NMR spectroscopy the NMR spin relaxation rates depend on both the global movement of protein and the local movements (Korchuganov et al, 2004; Lee et al, 2006). The Maxwell method and the DSE equation enable us to determine the correlation time $\tau_{2}$ which is not susceptible to internal motion of the protein. An accurate knowledge of this time may, in turn, help in the separation of the movements that influence the results obtained by other methods.

\section{CONCLUSIONS}

The overall motion correlation time $\tau_{2}$ of proteins in dilute solutions can be relatively easily and conveniently determine by using the Maxwell effect, if we experimentally determine the intrinsic viscosity. The results show that temperature has a strong influence on the value of $\tau_{2}$ : for each studied here albumin $\tau_{2}$ at a temperature of $5^{\circ} \mathrm{C}$ is approximately 3 times longer than at a temperature of $45^{\circ} \mathrm{C}$ (both in solutions at $\mathrm{pH}=\mathrm{pI}$ and at $\mathrm{pH}>\mathrm{pI}$ ). The values of the overall motion correlation time obtained for HSA, RSA, OSA, ESA and PSA in solutions at $\mathrm{pH}>\mathrm{pI}$ - at a fixed temperature - are only slightly different from each other. Similarly, $\tau_{2}$ determined for the BSA and HSA in solutions at $\mathrm{pH}=\mathrm{pI}$ are - at the same temperature - very similar, but differ significantly from the value of $\tau_{2}$ for albumins in solution at $\mathrm{pH}>\mathrm{pI}$. This is particularly evident for HSA, for which the values of $\tau_{2}$ were determined both in solution at the isoelectric point and beyond of it. The results obtained enable to postulate that, for a given protein and at a fixed temperature, $\tau_{2}$ reaches its highest value in the solution at isoelectric point. The values of $\tau_{2}$ obtained for the studied here albumins in solutions outside the isoelectric point agree very well with the values obtained using the Debye-Stokes-Einstein equation, wherein the hydrodynamic radius has been calculated for hydrated molecules.

\section{ACKNOWLEDGMENTS}

This work was supported by the project of MUS: KNW$1-111 / \mathrm{N} / 6 / \mathrm{I}$.

\section{REFERENCES}

Acuña A.U., González-Rod 
riguez J., Lillo M.P., Naqvi K. R.

(1987). Protein structure probed by polarization spectroscopy. II. A time-resolved fluorescence study of human fibrinogen. Biophys. Chem. 26, 63-70.

Baranowska H.M., Olszewski K.J. (1996). The hydration of proteins in solutions by self-diffusion coefficients NMR study. Biochim. Biophys. Acta 1289, 312-314.

Bialik C.N., Wolf B., Rachofsky E.L., Ross J.B.A., Laws W.R. (1998). Dynamics of biomolecules: assignment of local motions by fluorescence anisotropy decay. Biophys. J. 75, 2564-2573.

Bucci E., Steiner R. F. (1988). Anisotropy decay of fluorescence as an experimental approach to protein dynamics. Biophys. Chem. 30, 199-224.

Budak H., Köylü M.Z., Yilmaz U.N. (2006). The effective correlation time $\tau$ in jaw cysts determined from $400 \mathrm{MHz} \mathrm{T}_{1}$ and $\mathrm{T}_{2}$ measurements. Spectroscopy, 20, 177-183.

Carter D.C., Ho J.X. (1994). Advances in protein chemistry. Vol. 45, Academic Press, NY, pp. 153-203.

Cavalu S., Damian G., Dânşoreanu M. (2002). EPR study of non-covalent spin labeled serum albumin and hemoglobin. Biophys. Chem. 99, 181-188.

Cwietkow W. N., Eskin W. Je. \& Frenkel S. Ja. (1968). Structure of macromolecules in solutions. WNT: Warsaw.

Dais P., Vlachou S. (2001). ${ }^{13} \mathrm{C}$ nuclear magnetic relaxation study of segmental dynamics of the heteropolysaccharide pullulan in dilute solutions. Biomacromolecules, 2, 11371147.

Danielsen E., Bauer R., Schneider D. (1991). Rotational correlation times of peptides determined by perturbed angular correlations of $\gamma$-rays. Eur. Biophys. J. 20, 193-201.

Denisov V.P., Schlessman J.L., Garcia-Moreno E.B., Halle B. (2004). Stabilization of internal charges in a protein: Water penetration or conformational change? Biophys. J. 87, 39823994.

Denisov V.P., Halle B. (1995a). Protein hydration dynamics in aqueous solution: A comparison of bovine pancreatic trypsin inhibitor and ubiquitin by oxygen-17 spin relaxation dispersion. J. Mol. Biol. 245, 682-697.

Denisov V. P., Halle B. (1995b). Hydrogen exchange and protein hydration: The deuteron spin relaxation dispersions of bovine pancreatic trypsin inhibitor and ubiquitin. J. Mol. Biol. 245, 698-709.

Dockal M., Carter D. C., Rüker F. (1999). The three recombinant domains of human serum albumin. J. Biol. Chem. 274, 29303-29310.

Ebert B., Schwarz D., Lassmann G. (1981). Study of Brownian rotational motion in dense solutions of hemoglobin. Studia biophysica, 82, 105-112.

Einstein A. (1956). Investigations on the theory of the Brownian movement. Dover Publications, NY, pp.122.

Feinstein E., Deikus G., Rusinova E., Rachofsky E.L., Ross J.B.A. (2003). Constrained analysis of fluorescence anisotropy decay: application to experimental protein dynamics. Biophys. J. 84, 599-611.

Ferrer M.L., Duchowicz R., Carrasco B., Garcia de la Torre J., Acuña A.U. (2001). The conformation of serum albumin in solution: A combined phosphorescence depolarizationhydrodynamic modeling study. Biophys. J. 80, 2422-2430.

Grant E.H., South G.P., Takashima S., Ichimura H. (1971). Dielectric dispersion in aqueous solutions of oxyhaemoglobin and carboxyhaemoglobin. Biochem. J. 122,
691-699.

Gryczynski I., Cherek H., Lakowicz J.R. (1998). Detection of three rotational correlation times for a rigid asymmetric molecule using frequency-domain fluorometry. Biophys. Chem. 30, 271-277.

Harding S.E. (1997). The intrinsic viscosity of biological macromolecules. Progress in measurements, interpretation and application to structure in dilute solution. Prog. Biophys. Mol. Biol. 68, 207-262.

He X.M., Carter D.C. (1992). Atomic structure and chemistry of human serum albumin. Nature 358, 209-215.

Ho J.X., Holowachuk E.W., Norton E.J., Twigg P.D., Carter D.C. (1993). X-ray and primary structure of horse serum albumin (Equus caballus) at $0.27-\mathrm{nm}$ resolution. Eur. J. Biochem. 215, 205-212.

Hustedt E.J., Cobb C.E., Beth A.H., Beechem J.M. (1993). Measurement of rotational dynamics by the simultaneous nonlinear analysis of optical and EPR data. Biophys. $J$. 64, 614-621.

Isihara A. (1968). Irreversible processes in solutions of chain polymers. Adv. Polym. Sci. 5, 531-567.

Jachimska B., Wasilewska M, Adamczyk Z. (2008). Characterization of globular protein solutions by dynamic light scattering, electrophoretic mobility, and viscosity measurements. Langmuir, 24, 6866-6872.

Jeffery G.B. (1923). The motion of ellipsoidal particles immersed in a viscous fluid. Proc. Roy. Soc. A102, 161-179.

Kabir S.R., Yokoyama K., Mihashi K., Kodama T., Suzuki M. (2003). Hyper-mobile water is induced around actin filaments. Biophys. J. 85, 3154-3161.

Kakalis L.T., Kumosinski T.F. (1992). The dynamics of water in protein solutions: The field dispersion of deuterium NMR longitudinal relaxation. Biophys. Chem. 43, 39-49.

Kamal J.K.A., Behere D.V. (2002). Spectroscopic studies on human serum albumin and mthemalbumin: optical, steadystate, and picoseconds time-resolved fluorescence studies, and kinetics of substrate oxidation by methemalbumin. $J$. Biol. Inorg. Chem. 7, 273-283.

Korchuganov D.S., Gagnidze I.E., Tkach E.N., Schulga A.A., Kirpichnikov M.P., Arseniev A.S. (2004). Determination of protein rotational correlation time from NMR relaxation data at various solvent viscosities. J. Biomol. NMR 30, 431-442.

Kuttner Y.Y., Kozer N., Segal E., Schreiber G., Haran G. (2005). Separating the contribution of translational and rotational diffusion to protein association. J. Am. Chem. Soc. 127, 15138-15144.

Landau L. D., Lifshitz E. M. (1959). Fluid Mechanics. Pergamon, Oxford.

Lavalette D., Tétreau C., Toubez M., Blouquit Y. (1999). Microscopic viscosity and rotational diffusion of proteins in a macromolecular environment. Biophys. J. 76, 2744-2751.

Lee D., Hilty C., Wider G., Wüthrich K. (2006). Effective rotational correlation times of proteins from NMR relaxation interference. J. Magn. Reson. 178, 72-76.

Luchinat C., Parigi G. (2007). Collective relaxation of protein protons at very low magnetic field: a new window on protein dynamics and aggregation. J. Am. Chem. Soc. 129, 10551064.

Miller I., Gemeiner M. (1998). An electrophoretic study on interactions of albumins of different species with immobilized Cibacron Blue F3G A. Electrophoresis 19, 2506-2514. 
Miura M., Asaka N., Shinyashiki N., Mashimi S. (1994). Microwave dielectric study on bound water of globule proteins in aqueous solution. Biopolymers 34, 357-364.

Monkos K. (1996). Viscosity of bovine serum albumin aqueous solutions as a function of temperature and concentration. Int. J. Biol. Macromol. 18, 61-68.

Monkos K. (2004). On the hydrodynamics and temperature dependence of the solution conformation of human serum albumin from viscometry approach. Biochim. Biophys. Acta 1700, 27-34.

Monkos K. (2005a). A comparison of solution conformation and hydrodynamic properties of equine, porcine and rabbit serum albumin using viscometric measurements. Biochim. Biophys. Acta 1748, 100-109.

Monkos K. (2005b). Determination of some hydrodynamic parameters of ovine serum albumin solutions using viscometric measurements. J. Biol. Phys. 31, 219-232.

Monkos K. (2007a). Determination of the overall motion correlation time for some globular proteins in dilute solutions on the basis of Maxwell effect. Curr. Top. Biophys. 30, 7-14.

Monkos K. (2007b). Studies of protein solution conformations using viscometric measurements. [In:] Uversky V. \& Permyakov E. (eds.), Methods in protein structure and stability analysis. Part C. Conformational stability, size, shape and surface of protein molecules, Nova Science Publishers, New York, pp. 355-387.

Monkos K. (2013). A viscometric approach of $\mathrm{pH}$ effect on hydrodynamic properties of human serum albumin in the normal form. Gen. Physiol. Biophys. 32, 67-78.

Moser P., Squire P. G., O'Konski C. T. (1966). Electric polarization in proteins - dielectric dispersion and Kerr effect studies of isoionic bovine serum albumin. J. Phys. Chem. 70, 744-756.

Nesmelova I. V., Skirda V. D., Fedotov V. D. (2002). Generalized concentration dependence of globular protein self-diffusion coefficients in aqueous solutions. Biopolymers, 63, 132-140.

Perrin F. (1934). Mouvement brownien d'un ellipsoide: Dispersion dielectrique pour des molecules ellipsoidales. $J$. Phys. Radium Ser. VII. 5, 303-304.

Perrin F. (1936). Mouvement Brownien d'un ellipsoide. II Rotation libre de depolarization des fluorescence: Translation et diffusion de molecules ellipsoidales. $J$. Physique Radium 7, 1-11.

Raman C.V., Krishnan K.S. (1927). The Maxwell effect in liquids. Nature 120, 726-727.

Rezaei - Ghaleh N., Klama F., Munari F., Zweckstetter M. (2015). HYCUD: a computational tool for prediction of effective rotational correlation time in flexible proteins. Bioinformatics 31, 1319-1321.

Simha R. (1940). The influence of Brownian movement on the viscosity of solutions. J. Phys. Chem., 44, 25-34.

Squire P.G., Himmel M.E. (1979). Hydrodynamics and protein hydration. Arch. Biochem. Biophys. 196, 165-177.

Steinhoff H.J. (1988). A simple method for determination of rotational correlation times and separation of rotational and polarity effects from EPR spectra of spin-labeled biomolecules in a wide correlation time range. J. Biochem. Biophys. Methods 17, 237-248.

Steinhoff H.J., Lieutenant K., Schlitter J. (1989). Residual motion of hemoglobin - bound spin labels as a probe for protein dynamics. Z. Naturforsch. 44c, 280-288,

Steinhoff H.J. (1990). Residual motion of hemoglobin-bound spin labels and protein dynamics: viscosity dependence of the rotational correlation times. Eur. Biophys. J. 18, 57-62.

Takeda K., Yamamoto K. (1990). Fluorescence lifetime and rotational correlation time of bovine serum albumin-sodium dodecyl sulfate complex labeled with 1-dimethylaminonaphthalene-5-sulfonyl chloride: Effect of disulfide bridges in the protein on these fluorescence parameters. J. Protein Chem. 9, 17-22.

Takeda K., Yoshida I., Yamamoto K. (1991). Changes of fluorescence lifetime and rotational correlation time of bovine serum albumin labeled with 1 -dimethylaminonaphthalene-5-sulfonyl chloride in guanidine and thermal denaturations. J. Protein Chem. 10, 17-23.

Van-Quynh A., Willson S., Bryant R. G. (2003). Protein reorientation and bound water molecules measured by ${ }^{1} \mathrm{H}$ magnetic spin-lattice relaxation. Biophys. J. 84, 558-563.

Vlachou S., Politou A., Dais P., Mazeau K., Taravel F.R. (2001). Structure and dynamics of the branched polysaccharide scleroglucan in dilute solutions studied by 1D and 2D NMR spectroscopy. Carbohydr. Polym. 46, 349-363. Wüthrich K. (2003). NMR studies of structure and function of biological macromolecules (Nobel Lecture). J. Biomol. NMR 27, 13-39.

Yao S., Babon J.J., Norton R.S. (2008). Protein effective rotational correlation times from translational self-diffusion coefficients measured by PFG-NMR. Biophys. Chem. 136, $145-151$

Yilmaz A., Budak H., Ulak F.S. (2008). Determination of the effective correlation time modulating ${ }^{1} \mathrm{H}$ NMR relaxation processes of bound water in protein solutions. Magn. Reson. Imaging, 26, 254-260.

Yilmaz A., Zengin B., Ulak F.S. (2014). NMR proton spinlatice relaxation mechanism in $\mathrm{D}_{2} \mathrm{O}$ solutions of albumin determined at $400 \mathrm{MHz}$. J. Appl. Spectrosc. 81, 365-370.

Zeeb M., Jacob M.H., Schindler T., Balbach J. (2003). ${ }^{15} \mathrm{~N}$ relaxation study of the cold shock protein $\mathrm{CspB}$ at various solvent viscosities. J. Biomol. NMR 27, 221-234.

Zorrilla S., Rivas G., Acuña A.U., Lillo M.P. (2004). Protein self-association in crowded protein solutions: a timeresolved fluorescence polarization study. Protein Sci. 13, 2960-2969.

Zorrilla S., Hink M.A., Visser A.J.W.G., Lillo M.P. (2007). Translational and rotational motions of proteins in a protein crowded environment. Biophys. Chem. 125, 298-305. 